\title{
La epidemia de sarampión de 1899-1900 en Chile y la creación del primer hospital de niños de Santiago
}

\author{
ENRIQUE LAVAL R.
}

\author{
The measles epidemic in Chile 1899-1900 and the foundation \\ of the first pediatric hospital of Santiago
}

A principios del siglo XIX, había ya en las principales ciudades de Europa, "hospitales para niños", donde se formaron los entonces llamados "especialistas en enfermedades de niños". En Chile llegaron a crearse estos hospitales en el primer cuarto del siglo XX, existiendo desde los tiempos coloniales, solamente las Casas para Huérfanos ${ }^{1}$.

Desde más o menos en los últimos cuarenta años del siglo XIX, algunos médicos pensaban en la necesidad de contar en la capital con un establecimiento dedicado exclusivamente a la atención de los niños. Así, en 1861, el doctor Pablo Zorrilla escribía en los Anales de la Universidad de Chile una "Reseña de las causas de la morbilidad de los niños en Santiago y medios de evitarla". Entre las medidas que proponía para superar tantos males estaban la enseñanza de la higiene universal, la creación de hospitales especiales para los niños, establecimientos de casas de lactancia, la acción de comisiones encargadas de la difusión de la higiene"2.

En 1873, don Benjamín Vicuña Mackenna, Intendente de Santiago, hizo presente a la Junta de Beneficencia la necesidad de destinar el local que quedaba desocupado con el traslado de la Casa de la Maternidad al Hospital San Francisco de Borja, ubicado en Compañía esquina de Matucana, a anexo del Hospital San Juan de Dios y preferentemente a hospital de niños, del cual carecía la ciudad. Agregó que en caso que la Junta acordase establecer un hospital "para la curación y asistencia de niños pequeños", él ofrecía, desde luego hacer una imposición perpetua de un mil pesos a nombre de sus dos hijas pequeñas. Sin embargo, esta propuesta no tuvo acogida favorable a nivel gubernamental.

En 1886, la Facultad de Medicina se ocupó de la necesidad de crear la asistencia hospitalaria infantil y así lo hizo presente al Gobierno, el cual transcribió el acuerdo a la Junta de Beneficencia para organizar "la existencia en todos los hospitales de salas y dispensarios destinados a la asistencia de párvulos“. No obstante, nada se avanzó en este camino.

El 21 de noviembre de 1898, el Consejo Superior de Higiene Pública, hizo presente al Ministro del Interior y a la Junta de Beneficencia de Santiago la necesidad de instalar un hospital de niños, pues a la fecha no existía una sola cama para niños menores de 5 años. Diez años antes, en mayo de 1888, el doctor don Roberto Del Río fue llamado a servir la cátedra de Enfermedades de Niños, en el hospital San Juan de Dios, encontrando las máximas dificultades para el desempeño de sus funciones, iniciando la enseñanza en la Casa de Huérfanos, pues ni la administración del Hospital ni la Junta de Beneficencia consistieron en entregar a la docencia la sala San Ignacio de niños de dicho Hospital. En junio de ese año decía la Junta de Beneficencia al Gobierno: "la única sala para enfermedades de niños no podrá destinarse a la enseñanza del ramo a causa de la debilidad de su enmaderación, que no podría resistir el peso de muchas personas reunidas" 2 .

La triste realidad era que sólo se reservaba en los hospitales de Santiago, una sala para atender a los niños de 6 a 12 años ${ }^{4}$.

El doctor Ricardo Dávila Boza en 1899, en un informe sobre la "Mortalidad de los niños en Santiago, sus causas y sus remedios" señalaba en forma perentoria que "hoy en Santiago para combatir desde luego de una manera real y eficaz la horrenda mortalidad de párvulos, la principal de todas las medidas es única y exclusivamente, sin llegar a la más mínima duda, la fundación de un hospital especial para niños. Cada día que pasa nos conformamos de que con una mediana atención podría salvarse las tres cuartas partes de los niños que perecen miserablemente abandonados en sus enfermedades" 5 .

A fines de 1899, comenzó en Santiago y luego se extendió a casi todo el país, una de las más mortíferas epidemias de sarampión de las que se tenía recuerdo, continuando durante el año 1900, con una morbilidad y gravedad implacables. Al decir del profesor Puga Borne "fue la más tremenda experiencia que tuvimos en esa época, pues la epidemia nos ha llevado generación entera". Todo fue necesario improvisarlo. Con este motivo, don Manuel Arriarán Barros, fundó a sus expensas, el primer hospital de niños del país, que funcionó provisoriamente en la Casa de Ejercicios de San José, ubicada en Moneda esquina de Almirante Barroso, cedida en préstamo a la Beneficencia, por el arzobispo de Santiago Monseñor Mariano Casanova Vicuña, en octubre de 1900, en la cual inmediatamente se empezó a asistir a enfermos de sarampión ${ }^{3,6,8}$.

En ese mismo mes de octubre, la hospedería de San Rafael, en la calle Matucana, fue también habili- 
tada como hospital provisional para niños enfermos de sarampión ${ }^{9}$.

En septiembre de 1900, don Manuel Arriarán había llamado la atención de la Junta sobre la gravedad de la epidemia que "atribuyo a las pésimas condiciones económicas e higiénicas de las clases trabajadoras, y propuso abrir salas para niños en los establecimientos de Santiago solicitar de Gobierno \$10.000 para alimento y vestuario de niños de barrios más pobres e imprimir y repartir cartillas sanitarias sobre el modo de prevenir y curara el sarampión". La Junta de Beneficencia habilitó rápidamente dos salas para niños en el Hospital San José que se ocuparon en dos días ${ }^{3}$.

A la epidemia de sarampión se unieron en septiembre y octubre de 1900, otras de coqueluche y difteria $^{10}$.

En los primeros 25 días de funcionamiento del hospital provisional entraron 356 enfermos, 187 madres, muchas de ellas enfermas. Salieron sanos 204 niños, murieron 43 y quedaron en tratamiento 113 y 47 madres $^{3}$.

"El Mercurio" de Santiago del 26 de octubre de 1900, publicaba "que en 23 días la alfombrilla ha hecho aumentar en mil el número de niños fallecidos en el mismo periodo" 11 .

Según datos expuestos por el doctor Leopoldo Belloni P., en su "Contribución al estudio de la epidemia de alfombrilla de 1900 en Santiago", habrían fallecido en la capital cerca de 4.000 niños y no menos de 10.000 en toda la República. En esa misma época habrían padecido la enfermedad en Santiago alrededor de 40.000 niños y 60.000 en todo el territorio. ${ }^{10}$

A fines de noviembre de 1900, don Manuel Arriarán sugirió a la Junta de Beneficencia que el hospital provisional de niños podría trasladarse al local en que estaba la Protectora de la Infancia en la calle Matucana, entre Huérfanos y Compañía, pues en breve ocuparía sus nuevos edificios construidos a orillas del río Mapocho. El local que indicaba el señor Arriarán era de propiedad físcal y había estado destinado a Escuela Normal de Preceptores. Don Manuel Arriarán fue comisionado para gestionar la cesión del edificio. En pocos días obtuvo una resolución favorable del Gobierno y la Junta resolvió que el 15 de enero de 1901 se trasladaran los niños de la Casa de Ejercicios de San José, al local de Matucana, que quedaría a cargo de las Religiosas Hijas de San José Protectoras de la Infancia ${ }^{3}$.

A medida de que la población desvalida sabía que estaba en servicio un hospital de niños, acudía con sus hijos enfermos, aunque no siempre de coqueluche o sarampión, y de esa manera paulatinamente se ocuparon todas las camas, haciéndose imposible su clausura, so pena de arrojar a la calle a 300 o más enfermos. ${ }^{12}$

Para adoptar a su nuevo destino el edificio de la calle Matucana, hubo necesidad de ejecutar grandes reparaciones y construir algunas salas, así como departamentos de administración.

Fue designado Administrador del Hospital, don Manuel Arriarán y como Director Técnico, el eminente pediatra doctor don Roberto Del Río. A la muerte de don Manuel Arriarán en 1907, el doctor Del Río quedó a cargo de todas las funciones direc- tivas hasta su fallecimiento en 1917. Poco tiempo después, el Hospital de Niños pasó a llamarse Hospital Roberto Del Río, en homenaje a tan ilustre médico $^{1,2,8}$.

Es conveniente recordar que en enero de 1901, se promulgó la ley $\mathrm{N}^{\mathrm{o}} 1.408$, que autorizó la inversión de \$ 450.000 en la construcción de un hospital de niños. Con la imputación a esta ley, hasta 1908, sólo se había invertido la suma de $\$ 130.000$ en la adquisición de la quinta Lo Vicuña, situada en la Avenida Independencia, un poco al norte de la Escuela de Medicina. ${ }^{4}$

Tuvieron que pasar 36 años para que se iniciara la construcción del nuevo Hospital Roberto del Río. A fines de 1938 el edificio estaba en condiciones de ser habilitado y con motivo del terremoto del 24 de enero de 1939, el Gobierno solicitó a la Dirección General de Beneficencia, trasladar el Hospital Roberto Del Río al nuevo establecimiento, con el fin de albergar en el antiguo a los refugiados de la zona devastada. En 1940, se instaló ahí el denominado Hospital Nacional, que más tarde se transformó en la Maternidad Ángel Custodio Sanhueza. Finalmente, en ese lugar se inició en 1943, la construcción del nuevo Hospital San Juan de Dios.

La enseñanza de las llamadas "enfermedades de niños", comenzó a figurar ya en el famoso decreto del 19 de mayo de 1833 que llevaba la firma del Presidente Joaquín Prieto y de su Ministro don Joaquín Tocornal. Por el cual se "abriría en el Instituto Nacional un curso de ciencias médicas que duraría seis años", considerándose en el cuarto año el estudio de la "obstetricia y enfermedades incidentes de los niños". El doctor don Francisco Javier Tocornal fue el primer profesor de Enfermedades de Niños, designado en 1858.

De ahí en adelante, la pediatría iniciaría sus balbuceos, pero a pesar de todo la Facultad seguía considerándola "como la medicina del adulto, mirada por el revés de los gemelos del teatro, como alguien agudamente dijera", según lo anota el profesor doctor Eugenio Cienfuegos. ${ }^{2}$

\section{Bibliografía}

1.- Ariztía A. Homenaje a pediatras ilustres del pasado: los doctores Roberto del Río y Luis Calvo Mackenna. Rev Méd Chile 1976; 104: 251-6.

2.- Laval R E. Homenaje al Profesor Roberto Del Río. Conferencia dictada en el Hospital Roberto Del Río 16/03/1989 (inédita).

3.- Laval M E. Hospital Roberto Del Río. (apuntes inéditos).

4.- Poirier E. Chile en 1908. p. 210-211. Imprenta Barcelona. Santiago de Chile, 1909.

5.- Dávila B R. Mortalidad de los niños en Santiago sus causas y sus remedios. Rev Chil Hig 1899; 5: 265-392.

6.- Escobar T, Gallegos F. García M, Julian S. Fundaciones de Hospitales Pediátricos, 1900-1950. Unidad de Historia de la Medicina de Chile. 1999 (Pág. no numeradas).

7.- El Mercurio de Santiago. 15/10/1900.

8.- La Tercera de Santiago. 09/01/1998.

9.- El Mercurio de Santiago. 17/10/1900.

10.- Belloni P L. Contribución al estudio de la epidemia de alfombrilla de 1900 en Santiago. Imprenta San Buenaventura. Santiago de Chile. 1901; 5-48.

11.- El Mercurio de Santiago. 26/10/1900.

12.- Sánchez C. Hospital de Niños de Santiago. Informe. Rev Chil Hig 1902; 8: 389-412. 